
PREFERENCES

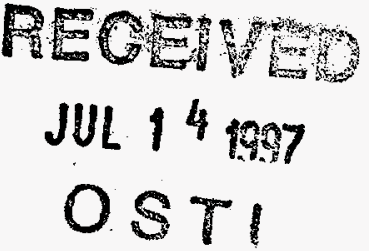

Submitted to:

For discussions outside the Laboratory

Date: April 1997
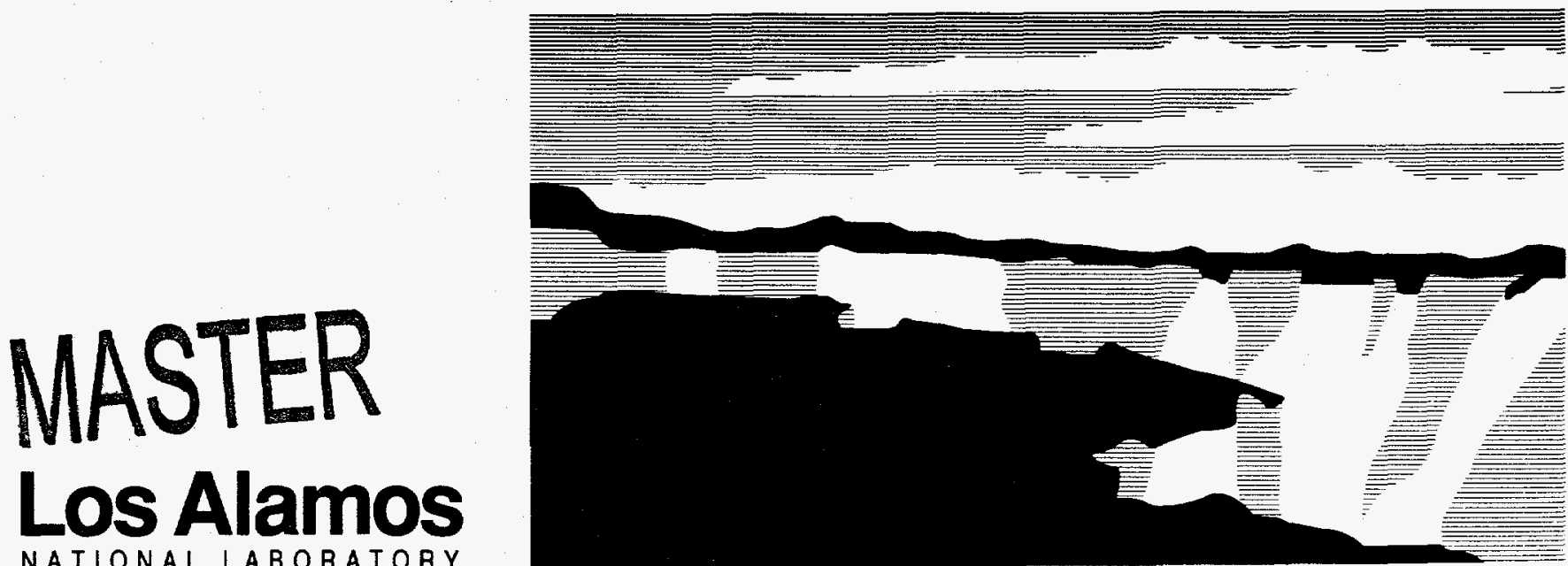

NATIONAL LABORATORY

Los Alamos National Laboratory, an affirmative action/equal opportunity employer, is operated by the University of California for the U.S. Department of Energy under contract W-7405-ENG-36. By acceptance of this article, the publisher recognizes that the U.S. Government retains a nonexclusive, royalty-free license to publish or reproduce the published form of this contribution, or to allow others to do so, for U.S. Government purposes. The Los Alamos National Laboratory requests that the publisher identify this article as work performed under the auspices of the U.S. Department of Energy 


\section{DISCLAMMER}

Portions of this document may be illegible in electronic image products. Images are produced from the best available original document. 


\section{DISCLAIMER}

This report was prepared as an account of work sponsored by an agency of the United States Government. Neither the United States Government nor any agency thereof, nor any of their employees, makes any warranty, express or implied, or assumes any legal liability or responsibility for the accuracy, completeness, or usefulness of any information, apparatus, product, or process disclosed, or represents that its use would not infringe privately owned rights. Reference herein to any specific commercial product, process, or service by trade name, trademark, manufacturer, or otherwise does not necessarily constitute or imply its endorsement, recornmendation, or favoring by the United States Government or any agency thereof. The views and opinions of authors expressed herein do not necessarily state or reflect those of the United States Government or any agency thereof. 


\title{
SENSITIVITY TO ATTACK PREFERENCES
}

\author{
Gregory H. Canavan
}

The relative preference for inflicting damage on the other and preventing damage to oneself, which was identified as a key uncertainty in earlier analytic models, is studied with exchange equations derived earlier, optimizing strikes for every value of this "relative preference" parameter. Conservative estimates of the other's preference could reduce stability indices significantly by shifting weapons from missile to value targets, which increases first strikes more than second.

Summary and conclusions. This note discusses the sensitivity of stability indices to relative preference between inflicting damage on others and preventing damage to oneself, which was identified as a key uncertainty in earlier analytic models. It uses the exchange equations derived earlier for mixes of missiles without defenses, optimizing strikes for every value of this "relative preference" parameter. The calculations show that conservative estimates of the other side's preference could reduce stability indices by about $50 \%$, which is as large an effect as produced by other factors studied. It does so by shifting weapons from missile to value targets, which increases first strikes more than second.

Review of previous model. For symmetric forces, it is possible to model exchanges in terms of the first, F, and second, S, strikes that either side could deliver. For a force of $M$ vulnerable missiles with $\mathrm{m}$ weapons each and $\mathrm{N}$ invulnerable missiles with $\mathrm{n}$ weapons each, of which a fraction $\mathrm{f}$ is directed at the opponent's missiles, the first strike on value targets is

$$
F=(1-f)(m M+n N) \text {; }
$$

thus, the average number of weapons delivered on each opponent vulnerable missile is

$$
\mathrm{r}=\mathrm{f}(\mathrm{mM}+\mathrm{nN}) / \mathrm{M} \text {. }
$$

For $\mathrm{r}$ large, the average probability of survival is approximately 1

$$
\mathrm{Q} \approx \mathrm{q}^{\mathrm{r}}
$$

where $q=1-p$, and $p$ is the attacking missile's single shot probability of kill, which is taken to be the same for all missiles. The second strike is

$$
\mathrm{S}=\mathrm{mMQ}+\mathrm{nN} \approx \mathrm{mMq}^{\mathrm{r}}+\mathrm{nN},
$$

which is delivered on value, as missiles remaining at the end of the exchange have no value.

Costs and stability index. Earlier notes discuss the conversion of these first and second strikes into the costs of striking first and second through exponential approximations to the fraction of the value targets destroyed by first and second strikes, ${ }^{2}$ which retains the structure of the full exchange while making the calculations and results easy to explore and interpret. The weighted sum of the first and second strike costs is a conventional metric for analysis. For symmetric forces the cost of striking first is 3 


$$
\mathrm{C}_{1}=\left(1-\mathrm{e}^{-\mathrm{kS}}+\mathrm{L} \mathrm{e}^{-\mathrm{kF}}\right) /(1+\mathrm{L})
$$

where $\mathrm{L}$ is the constant that represents the attacker's relative preference of inflicting damage on the other and preventing damage to self, which is the principal variable of concern here. The construction of $\mathrm{C}_{1}$ as a weighted average of cost to self and other is plausible, but not unique. ${ }^{4}$ The normalized second strike costs cost to the second striker is

$$
\mathrm{C}_{2}=\left(1-\mathrm{e}^{-\mathrm{kF}}+\mathrm{Le}^{-\mathrm{kS}}\right) /(1+\mathrm{L}) \text {, }
$$

which uses the same constant $L$ used above..$^{5}$ There is some additional arbitrariness in converting $C_{1}$ and $C_{2}$ into stability indices. ${ }^{6}$ For large forces, the ratio of costs $C_{1} / C_{2}$ is used below. If the cost of striking first, $\mathrm{C}_{1}$, is large, the first striker should be deterred from initiating an exchange. Similarly, if the cost of striking second, $\mathrm{C}_{2}$, is small, both sides should see little penalty in riding out a crisis. The ratio $\mathrm{C}_{1} / \mathrm{C}_{2}$ captures both of these effects in a single stability index

$$
\mathrm{I}=\mathrm{C}_{1} / \mathrm{C}_{2}=\left(1-\mathrm{e}^{-\mathrm{kS}}+\mathrm{Le} \mathrm{e}^{-\mathrm{kF}}\right) /\left(1-\mathrm{e}^{-\mathrm{kF}}+\mathrm{Le}-\mathrm{kS}\right)
$$

Results. While $L$ is usually thought of as being restricted to unity or less, there is no fundamental reason that has to be so. Larger values simply represent a preference for damaging the other over protecting oneself, which is not an irrational description of a possibly irrational opponent. Since the stability index weights the preferences $\mathrm{L}$ of both sides, it is important to bear in mind that the actual preference of ones opponent is not known; thus, it is prudent to examine larger values for conservatism. The calculations below vary $L$ by an order of magnitude to bound this uncertainty.

Figure 1 shows first and second strikes as functions of $L$ for $M=N=500$ missiles with $\mathrm{m}$ $=\mathrm{n}=6$ weapons per missile, i.e., roughly START I conditions. As $\mathrm{L}$ increases from a nominal value of 0.3 to $15, F$ increases from about 4,500 to 5,300 and $S$ increases from 3,000 to 3,500 . Figure 2 shows the reason for the increase in $S$ : as $L$ increases the probability of survival $Q$ increases from zero to about 0.2 , which means that the number of missiles in the second strike increases from 500 to $\approx 500+0.2 \times 500=600$ and the number of weapons to 3,600 .

Figure 3 shows the reason for this increase in Q: as $L$ increases, the increased preference for damage to other shifts weapons from missiles to value, and f falls from 0.25 to 0.1 . That allows $Q$ and hence $S$ to increase.

During this shift to larger $L$, the two costs fall in parallel, so that the difference between them becomes relatively more important. $B y L=13$, the stability index has fallen from 0.9 to 0.6 , which is about as large a fall as is produced by any other variable studied. Thus, these large force numerical models appear to confirm the result from earlier analytic studies that plausible excursions in $\mathrm{L}$ can produce large decreases in stability indices.

Summary and conclusions. This note discusses the sensitivity of stability indices to the relative preference between inflicting damage on the other and preventing damage to oneself, which was identified as a key uncertainty in earlier analytic models. It uses exchange equations 
derived earlier for mixes of missiles without defenses, optimizing strikes for every value of this "relative preference" parameter. Calculations show that conservative estimates of the other side's preference could reduce stability indices by $50 \%$, which is as large an effect as produced by other factors studied. It does so my shifting weapons from missile to value targets, which increases first strikes more than second. It would be useful to study these results with the full equations for unequal forces to see what new effects the ratio of preferences might produce.

\section{References}

1. G. Canavan, "Probability of Survival from Multiple Weapon Attacks," Los Alamos report LAUR-97-, February 1977.

2. G. Canavan, "Costs of Strikes Between Vulnerable Missile Forces," Los Alamos report LAUR-97-, February 1997.

3. G. Kent and R. DeValk, "Strategic Defenses and the Transition to Assured Survival," RAND Report R-3369-AF, October, 1986.

4. G. Canavan, "Stability at Symmetric Low Force Levels," op. cit.

5. G. Canavan, "Destabilizing Effects of Perceptions," op. cit..

6. G. Canavan, "Impact of Differing Metrics on Crisis Stability Analyses," A. Zichichi ed., International Seminar on Nuclear War and Planetary Emergencies, 18th Session: Global Stability Through Disarmament (London, World Scientific, 1993). 


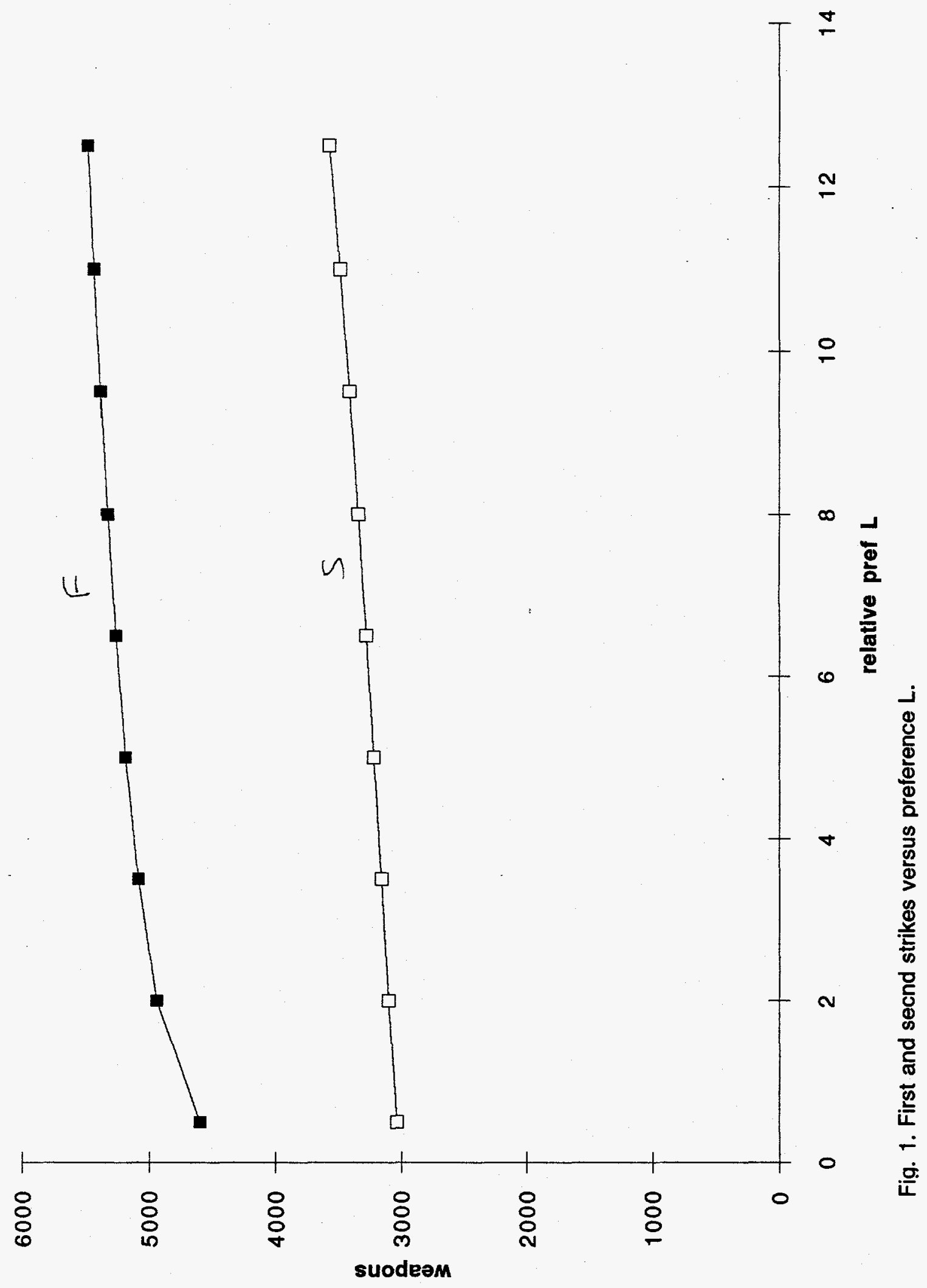


posb smar vo $L$
Ehart7

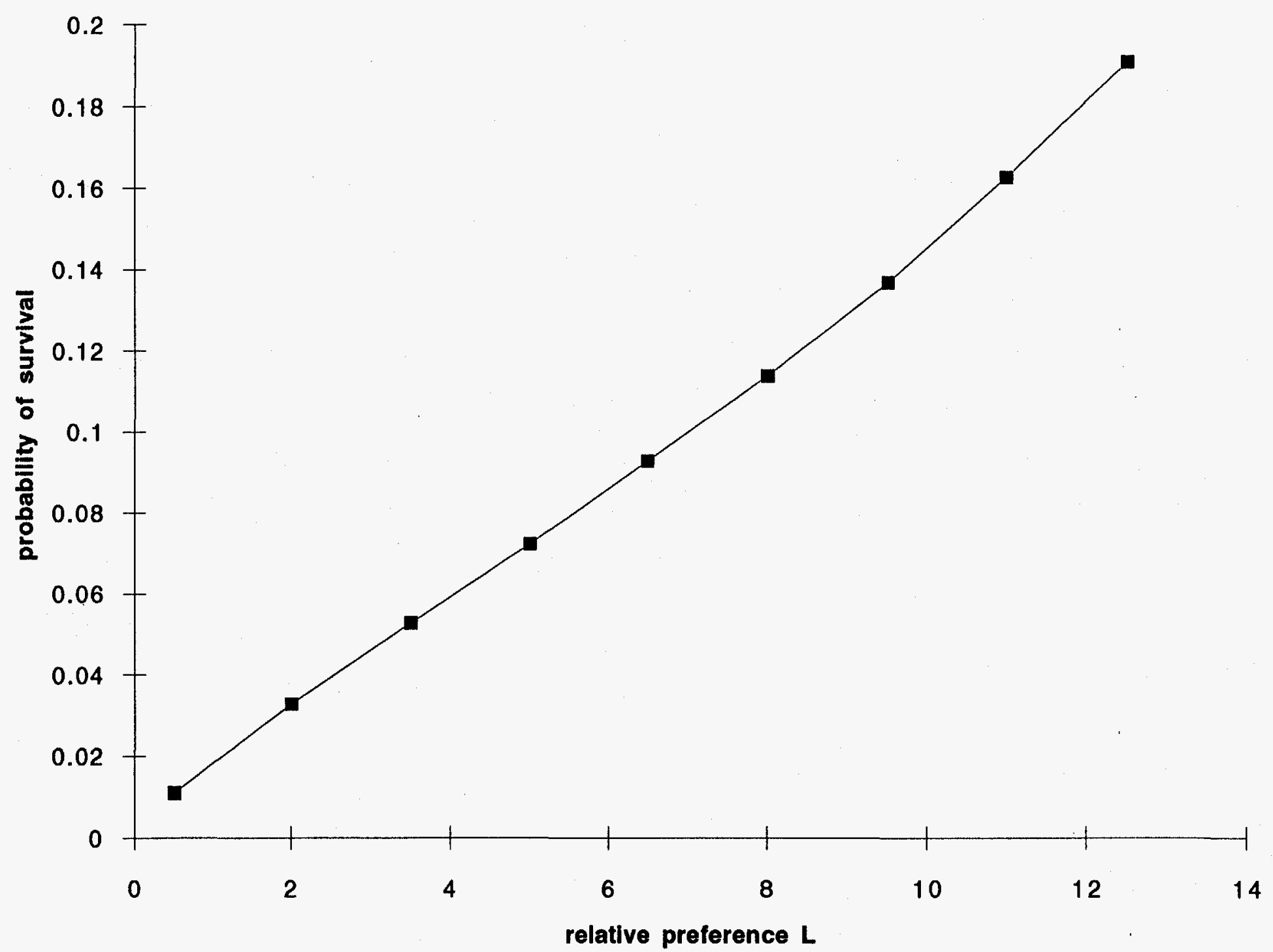

Fig. 2. Probability of surviving first strike versus relative preference. 


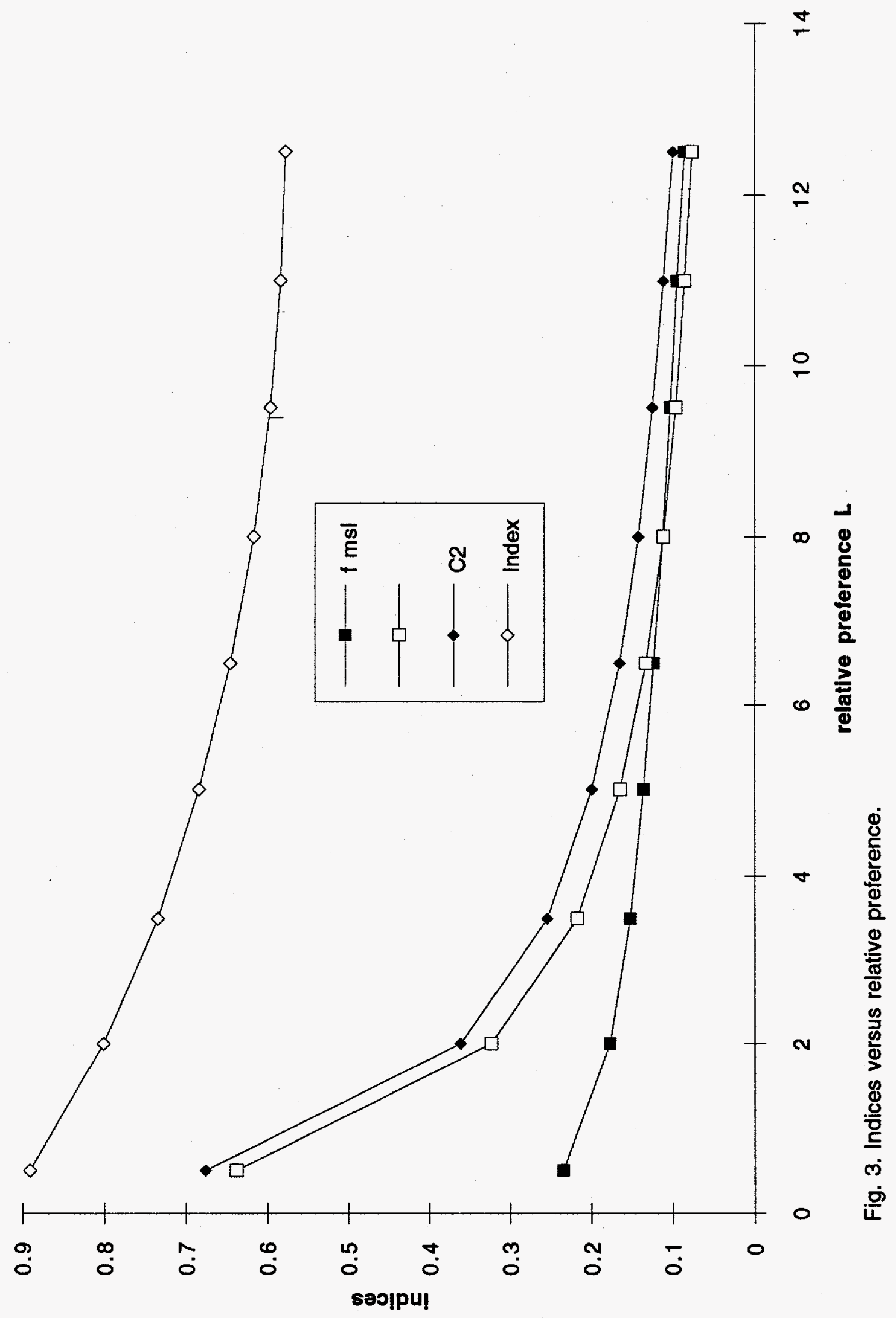

